\title{
La Inteligencia Emocional de docentes universitarios y su implicancia en estudiantes de ciencias experimentales
}

\author{
Bocco, María Inés ${ }^{1}$
}

Recibido: 31/08/2016

Aprobado: 30/11/2016

\section{Resumen}

El trabajo que se presenta forma parte de una Tesis de la Maestría en Didáctica de las Ciencias Experimentales de la Facultad de Bioquímica y Ciencias Biológicas (FBCB) de la Universidad Nacional del Litoral (UNL).

Consiste en el estudio de la relación que existe entre Capacidades de la Inteligencia Emocional (CIE) en docentes universitarios y el desempeño académico de estudiantes del ciclo básico de las carreras de Bioquímica y Licenciatura en Biotecnología de la UNL.

El termino Inteligencia Emocional (IE) surge de Salovey y Mayer (1990) y se refiere a la capacidad de reconocer nuestros propios sentimientos y de los demás, y de manejar bien las emociones. Además sostienen que la inteligencia interpersonal es un área de la IE, y la definen como la capacidad para comprender a los demás, entender cómo operan y cómo se debe trabajar cooperativamente.

La empatía, que se desprende de la inteligencia interpersonal, es la habilidad que se posee para entender lo que están sintiendo otras personas y ubicarse en situaciones desde su perspectiva. Esta habilidad social favorece el liderazgo, y puede ser usada para persuadir, dirigir, negociar y resolver situaciones que promuevan el trabajo en equipo.

Palabras clave: Inteligencia emocional, Capacidad empática, Profesores, Ciencias Experimentales, Universidad. 